\title{
Chronic thromboembolic pulmonary hypertension: animal models
}

\author{
Olaf Mercier and Elie Fadel
}

ABSTRACT: Chronic thromboembolic pulmonary hypertension (CTEPH) is a life-threatening disease due to pulmonary artery obstruction by persistent organised clots related to one or more episodes of acute pulmonary embolism. To date, the pathogenesis of CTEPH remains unexplained. Pulmonary endarterectomy removes obstruction from pulmonary vessels and can cure patients. However, some unreachable distal pulmonary obstruction and/or associated distal pulmonary vasculopathy could induce persistent pulmonary hypertension, the main postoperative complication.

The pathophysiology of CTEPH is not fully understood and improving knowledge of this disease could improve our future surgical and medical management. Many attempts, conducted over several decades, have failed to reproduce this chronic disease in animals. However, several animal models have provided insights into the pathophysiology and pathogenesis of CTEPH. Here, we review all the animal models that have improved the comprehension of CTEPH and hold promise for further investigations. This short review analyses strengths and weaknesses of all animal models available to study the pathophysiology of CTEPH.

KEYWORDS: Chronic thromboembolic pulmonary hypertension, pulmonary circulation, remodelling, right ventricular function

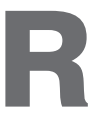
egarding the Dana Point 2009 clinical classification [1], chronic thromboembolic pulmonary hypertension (CTEPH) is a type- 4 subtype of pulmonary hypertension $(\mathrm{PH})$, in which pulmonary endarterectomy (PEA) [2] is effective in preventing death by right ventricle (RV) failure. CTEPH is due to obstruction of pulmonary arteries by persistent organised clots formed during one or more episodes of acute pulmonary embolism. The reason for clot persistence is unknown and the pathogenesis of CTEPH remains unexplained. To date, the lack of risk factors predicting the evolution from acute pulmonary embolism to CTEPH does not allow the development of preventive care and/or screening programmes.

The increase in pulmonary vascular resistance is believed to result from a combination of proximal pulmonary artery obstruction and distal pulmonary vasculopathy $[3,4]$, which have to be quantified before PEA to estimate risks and predict surgical success. However, the mechanisms underlying lesion development in the obstructed and unobstructed peripheral vascular beds remain unknown. Hence, medical management of inoperable CTEPH or operable CTEPH with an important distal vasculopathy remains troublesome because of a lack of efficient therapy.

To elucidate the pathophysiology of CTEPH, considerable effort has been expended in attempting to develop reliable animal models. Acute pulmonary embolism is easily produced in several animal species. In contrast, the induction of a disease replicating all the components of human CTEPH has proved challenging. These

Previous articles in this Series. No. 1: Delcroix M, Vonk-Noordegraaf A, Fadel E, et al. Vascular and right ventricular remodelling in chronic thromboembolic pulmonary hypertension. Eur Respir J 2013; 41: 224-232. No. 2: Lang IM, Pesavento R, Bonderman D, et al. Risk factors and basic mechanisms of chronic thromboembolic pulmonary hypertension: a current understanding. Eur Respir J 2013; 41: 462-468. No. 3: Jenkins DP, Madani M, Mayer E, et al. Surgical treatment of chronic thromboembolic pulmonary hypertension. Eur Respir J 2013; 41: 735-742. No. 4: Pepke-Zaba J, Jansa P, Kim NH, et al. Chronic thromboembolic pulmonary hypertension: role of medical therapy. Eur Respir J 2013; 41: 985-990.

AFFILIATION

Laboratory of Surgical Research and INSERM U999, Hôpital MarieLannelongue and Paris-Sud University, Le Plessis Robinson, France.

CORRESPONDENCE

0 . Mercier

Dept of Thoracic and Vascular

Surgery and Heart-Lung

Transplantation

Hôpital Marie-Lannelongue (Paris-

Sud University)

133 Avenue de la Résistance

Le Plessis Robinson

France

E-mail: 0.mercier@ccml.fr

Received:

July 022012

Accepted after revision:

Dec 082012

First published online:

Jan 112013 
components consist of clot persistence and organisation, pulmonary hypertension, chronic pulmonary-artery obstruction by unresolved intraluminal material, the development of a systemic blood supply to ischemic lung regions, pulmonary vasculopathy in unobstructed territories, and RV remodelling. Here, we review all the animal models described in the international literature that have been used to study the pathogenesis and pathophysiology of CTEPH (table 1).

\section{ANIMAL MODELS OF PERSISTENT INTRAVASCULAR THROMBOSIS}

The mechanisms by which the pulmonary emboli or thrombi fail to undergo lysis and instead organise into occluding fibrotic material remain unknown. Hypotheses include predisposing pulmonary endothelial cell abnormalities [42] and impairments in the vascular repair process [43]. A role for in situ thrombosis related to endothelial cell dysfunction may explain why up to $63 \%$ of patients with CTEPH have no documented history of acute pulmonary embolism [3]. This hypothesis has not been studied in animals, as no endothelial cell abnormalities have been identified to date in humans with CTEPH. In contrast, the process of thrombus organisation has been studied in reliable animal models of low flow-induced inferior vena cava thrombosis (table 2). Most of these animal models were developed in rodents, with the goal of investigating venous thrombus resolution [5-22]. Thrombosis can be induced by venous stasis alone or combined with induced blood hypercoagulability or mechanical endothelial damage. KANG et al. [13] studied a piglet model of jugular vein thrombosis after stenosis and mechanical endothelial damage [15]. Inferior vena cava occlusion has been also studied in monkeys [15]. However, mice and rats remain the most widely used animals due their cost-effectiveness and efficiency [7]. Low-flow rodent models are characterised by a laminar thrombus that resolves within 3-4 weeks via a process of recanalisation that requires inflammatory cell recruitment and angiogenic signals [5-11, 17-22].

In studies of clinical risk factors, CTEPH was associated neither with the classical plasma-factor abnormalities associated with venous thromboembolism nor with impairments in fibrinolysis. However, having a ventriculo-atrial shunt or history of pacemaker infection increased the risk of CTEPH [44, 45]. This finding prompted studies in animal models. Thus, BONDERMAN et al.[23] used a mouse model of low-flow venous thrombosis induced by inferior vena cava stenosis and endothelial damage to study the role for staphylococcal infection in delaying thrombus resolution and promoting the expression of profibrotic molecules.

\section{DUAL VASCULAR COMPARTMENT THEORY}

MOSER et al. [4] were the first to describe two compartments in the pulmonary vascular bed of CTEPH patients: an obstructed compartment subjected to chronic ischemia and an unobstructed compartment subjected to increased flow and shear stress (fig. 1). Thus, in addition to the obstruction of large pulmonary arteries, patients with CTEPH have vascular lesions in distal unobstructed territories. These distal lesions are similar to those found in patients with other forms of $\mathrm{PH}$.

Many observations are consistent with a role for both territories in increasing pulmonary-vascular resistance. First, for the same degree of pulmonary artery obstruction as measured by lung scanning, CTEPH is associated with higher pulmonary resistance values compared to acute pulmonary embolism [46]. Secondly, the onset of CTEPH disease is characterised by an asymptomatic honeymoon period during which pulmonary vascular resistance increases gradually without evidence of recurrent embolism. These two vascular

TABLE 1 Insights into thrombus resolution and organisation learned from stagnant flow induced inferior vena cava thrombus animal models

\begin{tabular}{|c|c|c|c|}
\hline Animal models & Species & Strengths & Weaknesses \\
\hline $\begin{array}{l}\text { IVC ligation or stenosis models } \\
\text { (0-28 days) }[5-23]\end{array}$ & Rodents, pig, primate & Reproduce thrombus resolution and organisation & $\begin{array}{c}\text { Studies on vein (not PA) } \\
\text { No PH } \\
\text { No additional vasculopathy } \\
\text { No pathogenesis }\end{array}$ \\
\hline $\begin{array}{l}\text { PA ligation models (5 weeks) } \\
\text { [24-35] }\end{array}$ & Rodents, pig & $\begin{array}{l}\text { Reproduce obstructed territories with post- } \\
\text { obstructive vasculopathy (bronchial } \\
\text { circulation, distal pulmonary vasculopathy) }\end{array}$ & $\begin{array}{c}\text { No PH } \\
\text { No RV remodelling and dysfunction } \\
\text { No distal vasculopathy in non-obstructed } \\
\text { lung }\end{array}$ \\
\hline $\begin{array}{l}\text { Pulmonary overflow models (aorto- } \\
\text { pulmonary shunt, 5-weeks overflow) } \\
\text { [36-40] }\end{array}$ & Pig & $\begin{array}{l}\text { Reproduce non-obstructed territories with distal } \\
\text { pulmonary vasculopathy with media thickness }\end{array}$ & $\begin{array}{l}\text { No pathogenesis } \\
\text { No post-obstructive vasculopathy } \\
\text { No pulmonary obstruction }\end{array}$ \\
\hline $\begin{array}{l}\text { PA ligation+glue embolisation } \\
\text { (5 weeks) [41] }\end{array}$ & Pig & $\begin{array}{c}\text { Reproduce obstructed and non-obstructed } \\
\text { territories } \\
\text { Reproduce RV remodelling and } \\
\text { dysfunction } \\
\text { Reproduce sustained PH }\end{array}$ & No pathogenesis \\
\hline
\end{tabular}

IVC: inferior vena cava; PA: pulmonary artery; $\mathrm{PH}$ : pulmonary hypertension; RV: right ventricle. 
TABLE 2 Current animal models used to study pathogenesis and pathobiology of chronic thromboembolic pulmonary hypertension

$\begin{array}{llll}\text { Year Animals } \quad \text { Models } & \text { Hypothesis }\end{array}$

Animal model of venous thrombosis MILLET [16]

Inflammation and

IVC thrombosis by ligation

\section{WAKEFIELD [17]}

LONDY [14]

HENKE [20]

VARMA [19]

HENKE [18

SINGH [12]

HUMPHRIES [11]

MCGUINNESS [9]

BONDERMAN [23]

Angiogenesis and

thrombus resolution

and organisation

WALTHAM [10]

WALTHAM [8]

WALTHAM [6]

MODARAl [7]
2005
Mice and CXCR2-/mice

Rat

Rat

Mice, tPA-/- mice, and $\mathrm{UPA}-/-$ mice

\section{Rat}

Rat

Mice

Rat and mice
Wessler stasis model (injection of serum+IVC temporary ligation)

IVC thrombosis by ligation or balloon occlusion

De-endothelialisation with $50 \%$ or $80 \%$ stenosis of jugular vein replacement of a venous segment by a Gore-Tex vascular prosthesis, \pm thromboplastin infusion IVC thrombosis by ligation external stenosis $\pm S$. aureus injection
IVC thrombosis by $80-90 \%$ external stenosis

IVC thrombosis by $80-90 \%$ external stenosis

IVC thrombosis by $80-90 \%$ external stenosis

IVC thrombosis by $80-90 \%$ external stenosis
Comparison of injection of homologous versus heterologous serum to obtain thrombus model

Thrombus ultrasound echogenicity could predict the age of clots in two different animal species

Description of six new animal models of venous thrombosis mimicking human disease

Thrombus ultrasound elasticity could predict clots age

Inflammation into the vein wall during thrombosis, extravasation of neutrophil and monocyte/macrophage: role of cytokines

Role of IL-8 in thrombus neovascularisation

Role of IL-10 in reducing perivenous inflammation quantified by MRI

Inflammation and thrombus resolution: role of neutrophil and its receptor CXCR2 Role of neutrophil in thrombus resolution

Role of IL-8 (pro-inflammatory and pro-angiogenic cytokine) in thrombus resolution

Role of UPA and TPA in thrombus resolution

\section{Role of MCP-1 in thrombus} resolution

Role of the monocytes in thrombus resolution

Role of $S$. aureus infection in misguiding thrombus resolution
Homologous serum induced the same thrombus than heterologous serum

Thrombus echogenicity could predict the age of the thrombus in rat and baboon and was correlated to the intrathrombus fibrin concentration

Spontaneous resolution of IVC thrombus induced progressive hardening with age that could be determined by duplex ultrasound

Neutrophil attractants (ENA-78, TNF- $\alpha$, IL-6, MCP-1) and monocyte/macrophage attractants (MIP- $1 \alpha$, ICAM-1, TNF- $\alpha$ ) increased during thrombus formation

IL8 augmented thrombus neovascularisation

MRI could quantify perivenous inflammation which is modified by IL-10 treatment

Thrombus resolution involved CXCR2 pathway

Neutropenia altered fibrinolytic activity slowing down thrombus resolution and increased intrathrombus collagen

IL-8 enhanced thrombus resolution and increased fibrosis by improving thrombus neovascularisation and increasing neutrophil

Unlike tPA, UPA induced monocytes recruitment into the thrombus and enhanced thrombus resolution

Injection of MCP-1 into the thrombus enhanced its organisation and resolution

Monocytes migrated into the thrombus during resolution

S. aureus thrombus infection enhanced fibrotic vascular remodelling after thrombosis misguiding natural resolution

Role of VEGF and bFGF in thrombus resolution

Role of VEGF in thrombus resolution

Effect of VEGF gene transfection on thrombus resolution

Effect of adenovirus-mediated

VEGF gene therapy on thrombus resolution
VEGF and bFGF had temporal expression patterns during thrombus resolution and organisation enhanced its resolution and organisation

Human VEGF gene plasmid transfection into the thrombus enhanced resolution and recanalisation Injection of adenovirus-mediated VEGF gene therapy enhanced thrombus resolution and recanalisation with macrophage recruitment Injection of VEGF in to the thrombus

IVC: inferior vena cava; ENA: extractable nuclear antigen; TNF- $\alpha$ : tumour necrosis factor- $\alpha$; IL: interleukin, MCP: monocyte-chemoattractant protein; MIP: macrophage inflammatory protein; ICAM: intercellular adhesion molecular; MRI: magnetic resonance imaging; tPA: tissue plasminogen activator; uPA: urokinase plasminogen activator; VEGF: vascular endothelial growth factor; bFGF: basic fibroblast growth factor; S. aureus: Staphylococcus aureus. 

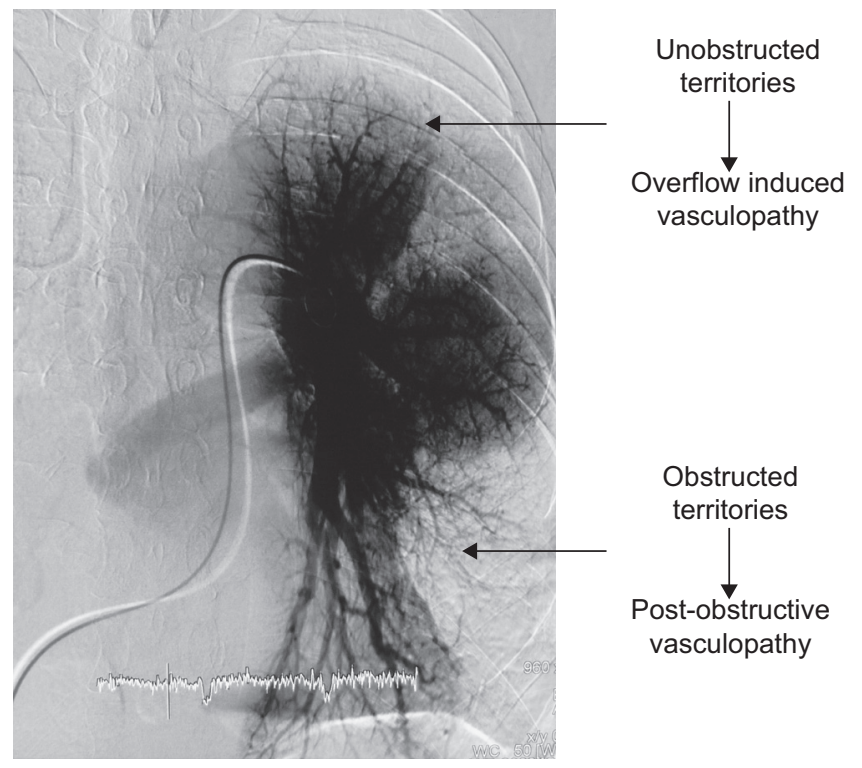

FIGURE 1. Anteroposterior pulmonary angiogram showing the two vascular territories in a patient with chronic thromboembolic pulmonary hypertension. The obstructed territory is subjected to chronic ischaemia and the unobstructed territory to an increase in blood flow.

compartments have been reproduced in animals separately and, more recently, simultaneously in a piglet model.

\section{MODELS REPLICATING PULMONARY ARTERY OBSTRUCTION}

The first attempt to replicate chronic pulmonary artery obstruction in an animal model was conducted in piglets by FADEL et al. [24] who used proximal embolisation of coils and tissue adhesive into the left pulmonary artery. Chronic obstruction (for 5 weeks) of the left pulmonary artery resulted in chronic lung ischemia without $\mathrm{PH}$. The result was an increase in the systemic blood supply to the lung via bronchial, mediastinal, and intercostal arteries, as well as distal post-obstructive pulmonary vasculopathy. These lesions were similar to those seen after chronic pulmonary artery ligation [25].

The left pulmonary artery was chosen for ligation, because it could be easily re-implanted into the main pulmonary artery to replicate reperfusion injuries after PEA. The systemic vascular response to chronic-pulmonary vascular obstruction differs across species, with proliferation of bronchial arteries into the intraparenchymal airways in large animals (dogs and piglets) and rats or of intercostal arteries into the pleural space in mice [26]. Although CTEPH studies have been conducted chiefly in piglets, a few studies of bronchial circulation have been performed in a rat model of pulmonary artery ligation [27]. Occlusion of one of the main pulmonary arteries stimulates angiogenesis in the bronchial vessels of the ipsilateral lung [28]. Bronchial arteries begin to enlarge as soon as 2-3 days after pulmonary artery ligation and supply the pulmonary circulation via precapillary anastomoses. These anastomoses may maintain airway epithelium oxygenation, thus explaining the lesser degree of reperfusion injury after chronic lung ischemia than after acute lung ischemia [29].
In addition to bronchial circulation hypertrophy, post-obstructive vasculopathy is characterised by pulmonary artery abnormalities including increased media thickness [30], impaired vasoreactivity [31], impaired endothelial nitric-oxide-synthase function [30], and increased reactivity to endothelin (ET)-1 [32] leading to increased resistance after reperfusion [33].

Lung reperfusion after chronic ischemia was followed by gradual reversal of the post-obstructive vasculopathy [25, 34], after an early phase of ischemia-reperfusion injury with endothelial cell damage [35].

Closure of the aorto-pulmonary shunt replicates the hemodynamic conditions in unobstructed territories after PEA. Shunt closure induced normalisation of ET-1 and ETA expression, followed by media hypertrophy reversal in the distal pulmonary arteries. These findings were consistent with the gradual improvement in pulmonary vascular resistance observed 36 months after PEA.

\section{MODELS REPLICATING LESIONS OF UNOBSTRUCTED PULMONARY ARTERIES}

During the early phase of CTEPH, the unobstructed territories are subjected to a chronic blood flow increase due to cardiac output redistribution. Therefore, systemic-to-pulmonary shunts have been used in animals to replicate the lesions seen in unobstructed territories in patients with CETPH [36]. In an animal model initially developed by RENDAS et al. [37] to replicate congenital heart disease, an aorto-pulmonary shunt is induced by implanting a short prosthesis between the ascending aorta and main pulmonary artery. This model has been used to induce high-flow pulmonary vascular lesions similar to those seen in unobstructed territories in CTEPH (fig. 2). As with the left pulmonary artery ligation models, the aorto-pulmonary shunt was achieved through a median sternotomy to avoid pleural opening and a subsequent inflammatory response. High-flow pulmonary vasculopathy induced by 5 weeks of aorto-pulmonary shunting was characterised by increased media thickness of the distal pulmonary arteries (fig. 3) related to smooth muscle cell proliferation (as shown by proliferating cell nuclear antigen labelling) and by elevated levels of ET-1 and its receptor endothelin receptor A (ETA) in lung tissue. ET-1 is a potent vasoconstrictor and mitotic peptide for vascular smooth muscle cells. ET-1 overexpression has been found in other animal models of high pulmonary flow [38-40]. ET-1 overproduction is probably a response to stimuli such as shear stress resulting from arterial pressure elevation [47].

\section{ANIMAL MODEL REPLICATING ALL FEATURES OF CTEPH}

Although the animal models described earlier provided useful information on impaired thrombus resolution and on the pathophysiology of lesions in obstructed and unobstructed territories, they failed to replicate important features of human CTEPH including pulmonary hypertension, interactions between the two pulmonary vascular compartments and, above all, RV remodelling and dysfunction.

Since the 1990s, several attempts to develop animal models of CTEPH [48-52] failed because of clot lysis by the very efficient endogenous fibrinolytic system [53] and of the remarkable 

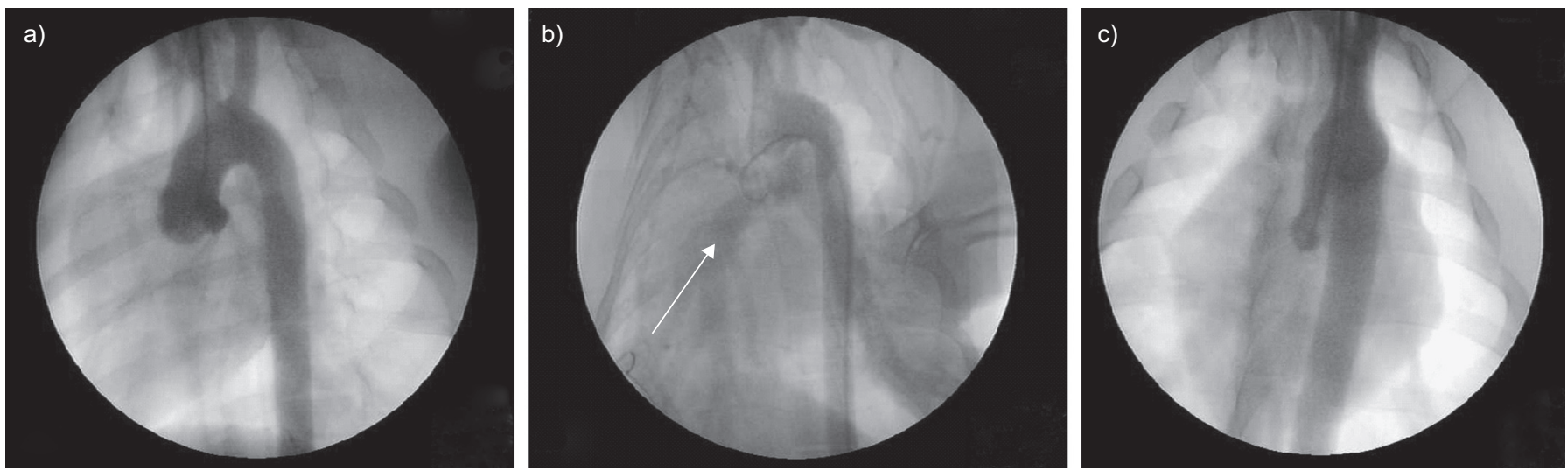

FIGURE 2. Aortography showing in a sham-group piglet. a) The aortic arch with the two supra-aortic arteries. b) Visualisation of the pulmonary vascular bed (white arrow) at the same time as the aortic arch after creation of an aorto-pulmonary shunt. c) No opacification of the pulmonary vascular bed after shunt closure.

adaptive capabilities of the pulmonary circulation. Thus, $3 \mathrm{~h}$ after acute pulmonary embolism in dogs [49], only $30 \%$ of the initial injected thrombus volume remained inside the pulmonary artery. Adding tranexamic acid [49] or plasminogen activator inhibitor-1 [50] to delay thrombus resorption between injections failed to solve this problem. The second difficulty was the large pulmonary circulation reserve, which required obstruction of more than half the pulmonary vasculature to achieve an increase in pulmonary vascular resistance. The adaptive capabilities of the pulmonary vasculature explain why repeated injections of small, inert, non-absorbable materials failed to replicate CTEPH. Thus, in a dog model of chronic pulmonary-artery injections of ceramic beads, $3 \mathrm{~mm}$ in diameter, pulmonary pressures and resistances returned to normal within 1 week after each injection [51]. With 100$300 \mu \mathrm{m}$ microspheres, 60 days of repeated embolisation were required to increase the pulmonary-artery pressure [52]. After

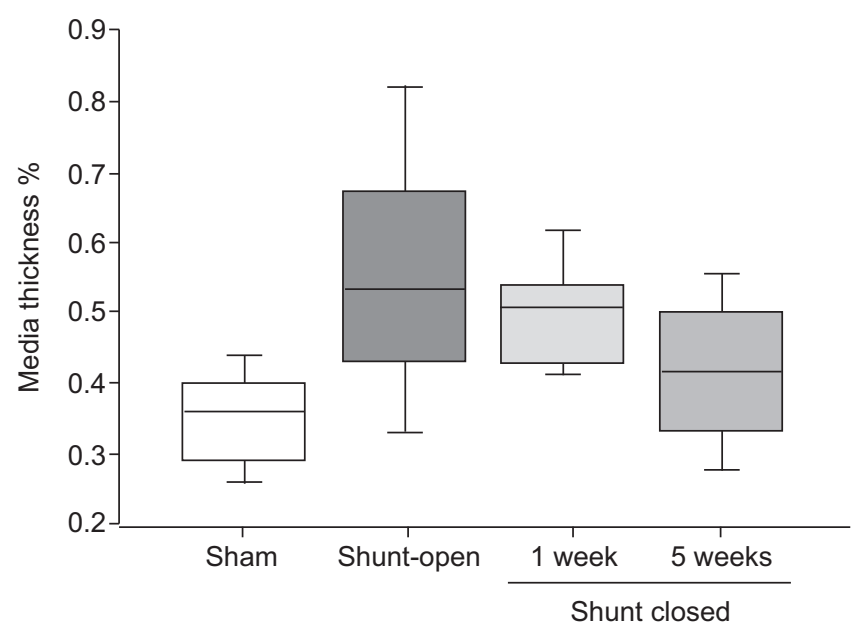

FIGURE 3. Box plot of media thickness as a percentage of small pulmonary arteries $(<150 \mu \mathrm{m})$ calculated in: the sham $(35.9 \pm 0.8 \%)$, shunt-open $(55.6 \pm 1.2 \%)$, 1-week shunt-closed $(48.7 \pm 1 \%)$, and 5 -weeks shunt-closed $(40.9 \pm 1 \%)$ groups [36]. Media thickness percentage was calculated as follows: external diameter minus internal diameter and divided by the external diameter. Aorto-pulmonary shunting was created by a graft interposition between the ascending aorta and the pulmonary trunk in piglets. Closure of the shunt was obtained by dividing the graft.
60 days, signs of $\mathrm{PH}$ started to develop, but there was no bronchial artery hypertrophy, post-obstructive or high-flow vasculopathy, or proximal vascular obstruction [52]. A third challenge lies in replicating RV remodelling. Extensive acute obstruction of the pulmonary arterial tree is usually lethal by heart failure in the absence of previous RV training and hypertrophy. To tolerate a persistent increase in pulmonary arterial pressure, the RV must undergo remodelling, which consists in gradual ventricular wall hypertrophy followed by right-heart-chamber enlargement with a paradoxical septal motion. In the event of persistent pulmonary hypertension, RV failure develops.

We recently developed a CTEPH piglet model [41], consisting of a primary left pulmonary artery ligation via a sternotomy that was followed by weekly transcatheter embolisations, under fluoroscopic control, of the tissue adhesive enbucrilate (Histoacryl) into the right lower lobe for 5 weeks. Pulmonary artery ligation overwhelmed the pulmonary circulation reserve and led to PH within a few weeks, with progressive obstruction of the remaining lung vasculature. The progressive nature of the obstruction achieved via weekly embolisation allowed the RV to adapt to the pressure increase, thus preventing death by acute RV failure. The tissue adhesive enbucrilate solidifies immediately after contact with blood and adheres to the arterial wall. The result was proximal obstruction by unresolved material in the right lower-lobe artery. Thus, the right upper-lobe arteries remained patent and exhibited lesions replicating those seen in unobstructed territories in CTEPH. After 5 weeks, this piglet model replicated all the features of human CTEPH: increased pulmonary vascular resistance, increased mean pulmonary artery pressure, increased media thickness of distal pulmonary arteries in both obstructed and unobstructed territories, increased systemic blood supply through the bronchial arteries in the obstructed territories, RV hypertrophy, RV enlargement, and paradoxical septal motion (fig. 4). Interestingly, although the embolisations were stopped after 5 weeks, the increase in pulmonary vascular resistance persisted for up to 1 month later after the last embolisation (unpublished data). Overexpression of ET-1 and its receptors ETA and ETB was documented in the remodelled distal arteries of the unobstructed territories, in keeping with previous findings in 


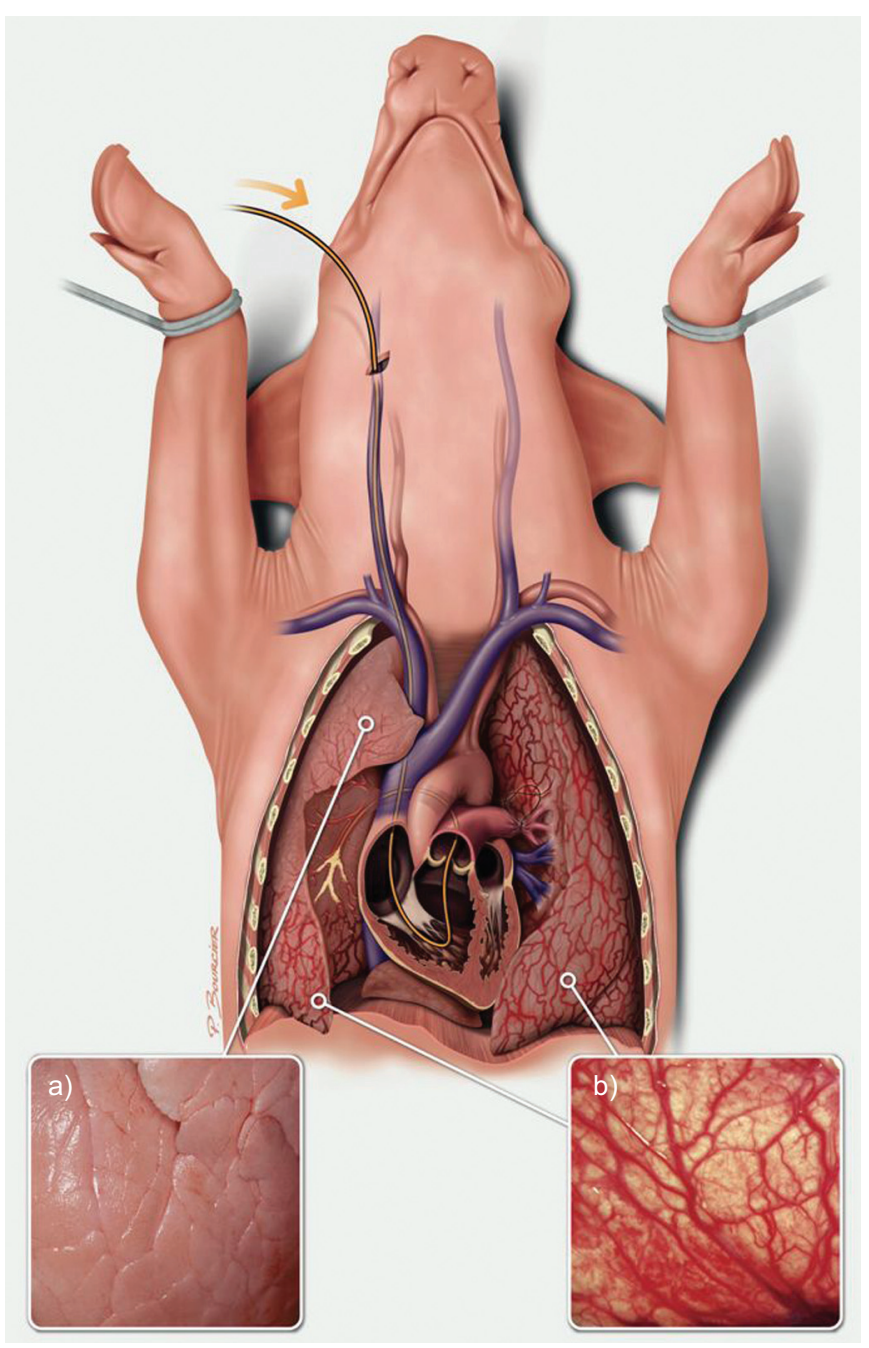

FIGURE 4. Chronic thromboembolic pulmonary hypertension piglet model consisting of left pulmonary artery ligation and repeated embolisation in the right lower lobe: bronchial artery hypertrophy in the ischaemic lung territory (b), apparently normal right upper lobe (a), unresolved intravascular material made of tissue adhesive and fibrin moulding the arterial tree, and right ventricle remodelling.

piglets with high-flow vasculopathy [36, 38]. In addition, ETA overexpression in the obstructed territories was consistent with the results of previous studies of post-obstructive vasculopathy [33]. Further experiments are needed to monitor pulmonary resistance at a distance from the last pulmonary embolisation, to investigate RV remodelling and failure, and to assess interactions between the obstructed and unobstructed territories. However, one should bear in mind that this model does not replicate the impaired thrombus resolution seen in human CTEPH.

\section{CONCLUSIONS}

Animal models developed over several decades have provided valuable information on the pathophysiology of CTEPH. Thrombus resolution and obstructed and unobstructed territories have been studied separately in several animal models. Recently, a model replicating all the major aspects of human CTEPH was developed. This model should prove useful for investigating RV dysfunction and distal lung vessel abnormalities. However, additional models are still needed to elucidate the pathobiology of thrombus persistence.

\section{STATEMENT OF INTEREST}

None declared.

\section{REFERENCES}

1 Simonneau G, Robbins IM, Beghetti M, et al. Updated clinical classification of pulmonary hypertension. J Am Coll Cardiol 2009; 54: Suppl. 1, S43-S54.

2 Dartevelle P, Fadel E, Mussot S, et al. Chronic thromboembolic pulmonary hypertension. Eur Respir J 2004; 23: 637-648.

3 Hoeper MM, Mayer E, Simonneau G, et al. Chronic thromboembolic pulmonary hypertension. Circulation 2006; 113: 2011-2020.

4 Moser KM, Bloor CM. Pulmonary vascular lesions occurring in patients with chronic major vessel thromboembolic pulmonary hypertension. Chest 1993; 103: 685-692.

5 Modarai B, Humphries J, Burnand KG, et al. Adenovirus-mediated VEGF gene therapy enhances venous thrombus recanalization and resolution. Arterioscler Thromb Vasc Biol 2008; 28: 1753-1759.

6 Waltham M, Burnand K, Fenske C, et al. Vascular endothelial growth factor naked DNA gene transfer enhances thrombus recanalization and resolution. J Vasc Surg 2005; 42: 1183-1189.

7 Modarai B, Burnand KG, Humphries J, et al. The role of neovascularisation in the resolution of venous thrombus. Thromb Haemost 2005; 93: 801-809.

8 Waltham M, Burnand KG, Collins M, et al. Vascular endothelial growth factor enhances venous thrombus recanalisation and organisation. Thromb Haemost 2003; 89: 169-176.

9 McGuinness CL, Humphries J, Waltham M, et al. Recruitment of labelled monocytes by experimental venous thrombi. Thromb Haemost 2001; 85: 1018-1024.

10 Waltham M, Burnand KG, Collins M, et al. Vascular endothelial growth factor and basic fibroblast growth factor are found in resolving venous thrombi. J Vasc Surg 2000; 32: 988-996.

11 Humphries J, McGuinness CL, Smith A, et al. Monocyte chemotactic protein-1 (MCP-1) accelerates the organization and resolution of venous thrombi. J Vasc Surg 1999; 30: 894-899.

12 Singh I, Burnand KG, Collins M, et al. Failure of thrombus to resolve in urokinase-type plasminogen activator gene-knockout mice: rescue by normal bone marrow-derived cells. Circulation 2003; 107: 869-875.

13 Kang C, Bonneau M, Brouland JP, et al. In vivo pig models of venous thrombosis mimicking human disease. Thromb Haemost 2003; 89: 256-263.

14 Londy FJ, Kadell AM, Wrobleski SK, et al. Detection of perivenous inflammation in a rat model of venous thrombosis using MRV. J Invest Surg 1999; 12: 151-156.

15 Fowlkes JB, Strieter RM, Downing LJ, et al. Ultrasound echogenicity in experimental venous thrombosis. Ultrasound Med Biol 1998; 24: $1175-1182$.

16 Millet J, Vaillot M, Theveniaux J, et al. Experimental venous thrombosis induced by homologous serum in the rat. Thromb Res 1996; 81: 497-502.

17 Wakefield TW, Linn MJ, Henke PK, et al. Neovascularization during venous thrombosis organization: a preliminary study. J Vasc Surg 1999; 30: 885-892.

18 Henke PK, Wakefield TW, Kadell AM, et al. Interleukin-8 administration enhances venous thrombosis resolution in a rat model. J Surg Res 2001; 99: 84-91.

19 Varma MR, Varga AJ, Knipp BS, et al. Neutropenia impairs venous thrombosis resolution in the rat. J Vasc Surg 2003; 38: 1090-1098.

20 Henke PK, Varga A, De S, et al. Deep vein thrombosis resolution is modulated by monocyte CXCR2-mediated activity in a mouse model. Arterioscler Thromb Vasc Biol 2004; 24: 1130-1137. 
21 Xie H, Kim K, Aglyamov SR, et al. Staging deep venous thrombosis using ultrasound elasticity imaging: animal model. Ultrasound Med Biol 2004; 30: 1385-1396.

22 Wakefield TW, Strieter RM, Wilke CA, et al. Venous thrombosisassociated inflammation and attenuation with neutralizing antibodies to cytokines and adhesion molecules. Arterioscler Thromb Vasc Biol 1995; 15: 258-268.

23 Bonderman D, Jakowitsch J, Redwan B, et al. Role for staphylococci in misguided thrombus resolution of chronic thromboembolic pulmonary hypertension. Arterioscler Thromb Vasc Biol 2008; 28: 678-684.

24 Fadel E, Riou JY, Mazmanian M, et al. Pulmonary thromboendarterectomy for chronic thromboembolic obstruction of the pulmonary artery in piglets. J Thorac Cardiovasc Surg 1999; 117: 787-793.

25 Fadel E, Michel RP, Eddahibi S, et al. Regression of postobstructive vasculopathy after revascularization of chronically obstructed pulmonary artery. J Thorac Cardiovasc Surg 2004; 127: 1009-1017.

26 Mitzner W, Wagner EM. Vascular remodeling in the circulations of the lung. J Appl Physiol 2004; 97: 1999-2004.

27 Wagner EM, Jenkins J, Perino MG, et al. Lung and vascular function during chronic severe pulmonary ischemia. J Appl Physiol 2011; 110: 538-544.

28 Charan NB, Carvalho P. Angiogenesis in bronchial circulatory system after unilateral pulmonary artery obstruction. J Appl Physiol 1997; 82: 284-291.

29 Fadel E, Mazmanian GM, Chapelier A, et al. Lung reperfusion injury after chronic or acute unilateral pulmonary artery occlusion. Am J Respir Crit Care Med 1998; 157: 1294-1300.

30 Fadel E, Mazmanian GM, Baudet B, et al. Endothelial nitric oxide synthase function in pig lung after chronic pulmonary artery obstruction. Am J Respir Crit Care Med 2000; 162: 1429-1434.

31 Shi W, Hu F, Kassouf W, et al. Altered reactivity of pulmonary vessels in postobstructive pulmonary vasculopathy. J Appl Physiol 2000; 88: 17-25.

32 Shi W, Giaid A, Hu F, et al. Increased reactivity to endothelin of pulmonary arteries in long-term post-obstructive pulmonary vasculopathy in rats. Pulm Pharmacol Ther 1998; 11: 189-196.

33 Michel RP, Hakim TS. Increased resistance in postobstructive pulmonary vasculopathy: structure-function relationships. J Appl Physiol 1991; 71: 601-610.

34 Fadel E, Wijtenburg E, Michel R, et al. Regression of the systemic vasculature to the lung after removal of pulmonary artery obstruction. Am J Respir Crit Care Med 2006; 173: 345-349.

35 Sage E, Mercier O, Van den Eyden F, et al. Endothelial cell apoptosis in chronically obstructed and reperfused pulmonary artery. Respir Res 2008; 9: 19.

36 Mercier O, Sage E, de Perrot M, et al. Regression of flow-induced pulmonary arterial vasculopathy after flow correction in piglets. J Thorac Cardiovasc Surg 2009; 137: 1538-1546.
37 Rendas A, Lennox S, Reid L. Aorta-pulmonary shunts in growing pigs. Functional and structural assessment of the changes in the pulmonary circulation. J Thorac Cardiovasc Surg 1979; 77: 109-18.

38 Rondelet B, Kerbaul F, Motte S, et al. Bosentan for the prevention of overcirculation-induced experimental pulmonary arterial hypertension. Circulation 2003; 107: 1329-1335.

39 Reddy VM, Wong J, Liddicoat JR, et al. Altered endotheliumdependent responses in lambs with pulmonary hypertension and increased pulmonary blood flow. Am J Physiol 1996; 271: H562H570.

40 Ovadia B, Reinhartz O, Fitzgerald R, et al. Alterations in ET-1, not nitric oxide, in 1-week-old lambs with increased pulmonary blood flow. Am J Physiol Heart Circ Physiol 2003; 284: H480-H490.

41 Mercier O, Tivane A, Raoux F, et al. A reliable piglet model of chronic thrombo-embolic pulmonary hypertension. Am J Respir Crit Care Med 2011; 183: A2415.

42 Egermayer P, Peacock AJ. Is pulmonary embolism a common cause of chronic pulmonary hypertension? Limitations of the embolic hypothesis. Eur Respir J 2000; 15: 440-448.

43 Lang I. Advances in understanding the pathogenesis of chronic thromboembolic pulmonary hypertension. Br J Haematol 2010; 149: 478-483.

44 Bonderman D, Wilkens H, Wakounig S, et al. Risk factors for chronic thromboembolic pulmonary hypertension. Eur Respir J 2009; 33: 325-331.

45 Bonderman D, Jakowitsch J, Adlbrecht C, et al. Medical conditions increasing the risk of chronic thromboembolic pulmonary hypertension. Thromb Haemost 2005; 93: 512-516.

46 Azarian R, Wartski M, Collignon MA, et al. Lung perfusion scans and hemodynamics in acute and chronic pulmonary embolism. J Nucl Med 1997; 38: 980-983.

47 Galié N, Manes A, Branzi A. The endothelin system in pulmonary arterial hypertension. Cardiovasc Res 2004; 61: 227-237.

48 Moser KM, Guisan M, Bartimmo EE, et al. In vivo and post mortem dissolution rates of pulmonary emboli and venous thrombi in the dog. Circulation 1973; 48: 170-178.

49 Moser KM, Cantor JP, Olman M, et al. Chronic pulmonary thromboembolism in dogs treated with tranexamic acid. Circulation 1991; 83: 1371-1379.

50 Marsh JJ, Konopka RG, Lang IM, et al. Suppression of thrombolysis in a canine model of pulmonary embolism. Circulation 1994; 90: 3091-3097.

51 Kim H, Yung GL, Marsh JJ, et al. Endothelin mediates pulmonary vascular remodelling in a canine model of chronic embolic pulmonary hypertension. Eur Respir J 2000; 15: 640-648.

52 Sato H, Hall CM, Griffith GW, et al. Large animal model of chronic pulmonary hypertension. ASAIO J 2008; 54: 396-400.

53 Lang IM, Marsh JJ, Konopka RG, et al. Factors contributing to increased vascular fibrinolytic activity in mongrel dogs. Circulation 1993; 87: 1990-2000. 